\title{
The Crystal Structure of Bis(tetrahydrothiophene)silver(I)
}

\section{Tetrafluoroborate}

\author{
BERTIL NORÉN and ÅKE OSKARSSON
}

Inorganic Chemistry 1, Chemical Center, Box 124, S-221 00 Lund, Sweden

The crystal structure of $\left[\mathrm{Ag}\left(\mathrm{C}_{4} \mathrm{H}_{8} \mathrm{~S}\right)_{2}\right] \mathrm{BF}_{4}$ has been determined from $\mathrm{X}$-ray intensity data collected at $200 \mathrm{~K}$ with a four-circle diffractometer. The space group is $P 2_{1} 2_{1} 2_{1}$ with $Z=4$; $a=7.497(2), b=11.432(3)$ and $c=15.249(3) \AA$. The refinement converged to $R=0.031$. The coordination geometry around silver is close to trigonal planar, with $\mathrm{Ag}-\mathrm{S}$ distances in the range $2.44-2.56 \AA$ and $\mathrm{S}-\mathrm{Ag}-\mathrm{S}$ angles in the range $116-125^{\circ}$. Three-coordination is achieved through bridging by one of the two crystallographically independent sulphur atoms, and infinite chains $\cdots \mathrm{S}-\mathrm{Ag}-\mathrm{S}-\mathrm{Ag} \cdot \cdots$ are formed along $a$. These chains are van der Waals packed with the $\mathrm{BF}_{4}^{-}$ions situated in voids in the vicinity of the $\mathrm{Ag}(\mathrm{I})$. The two closest distances, $\mathrm{B} \cdots \mathrm{Ag}$ in adjacent chains, are 3.73 and $6.69 \AA$, respectively, indicating that the $\mathrm{BF}_{4}^{-}$ions have little bridging effects between the chains.

From a comparison with other compounds, in which $S$ is the only donor atom, it is concluded that $\mathrm{Ag}(\mathrm{I})$ is quite variable in its coordination geometry with $\mathrm{S}$. The coordination geometries observed are bent, trigonal planar and tetrahedral for coordination numbers 2,3 and 4, respectively.

This is the first paper in a series dealing with the coordination geometry in silver(I)tetrahydrothiophene systems. The nature of the anion is systematically changed from one with very poor donor properties, e.g. $\mathrm{BF}_{4}^{-}$, to those with good donor properties, e.g. $\mathrm{I}^{-}$.

In such a series there is an increasing competition between the tetrahydrothiophene molecule (THT) and the anions for the coordination sites around $\operatorname{Ag}(\mathrm{I})$. The aim is to elucidate the correlation between the concepts hard-soft as derived from thermodynamic parameters of complex formation in solution ${ }^{1,2}$ and the observed coordination geometries (coordination figures and bond distances). The crystal structure of $\left[\mathrm{Ag}(\mathrm{THT})_{2}\right] \mathrm{BF}_{4}$ is reported below.

\section{EXPERIMENTAL}

The title compound was prepared by dissolving $\mathrm{Ag}_{2} \mathrm{O}$ in an aqueous solution of $\mathrm{HBF}_{4} . \mathrm{Ag}^{+} \mathrm{BF}_{4}^{-}$ was then extracted into THT. After centrifugation the water phase was discarded, the THTphase was diluted with $\mathrm{CH}_{2} \mathrm{Cl}_{2}$, dried over molecular sieves and filtered through a G4 glass filter. The methylene chloride was then evaporated under reduced pressure $(20 \mathrm{mmHg})$ at room temperature. Finally, crystals of $\left[\mathrm{Ag}(\mathrm{THT})_{2}\right] \mathrm{BF}_{4}$ were obtained by evaporating the excess tetrahydrothiophene at a reduced pressure of $0.08 \mathrm{mmHg}$. Recrystallization from ethyl acetate gave single crystals. The silver content was determined by potentiometric titrations with a sodium chloride solution. Before a titration the tetrahydrothiophene was destroyed by heating the compound with concentrated $\mathrm{HNO}_{3}$ and $\mathrm{H}_{2} \mathrm{O}_{2}$. The titration results were evaluated according to Gran, ${ }^{3}$ giving $29.1 \pm 0.1 \%$ $\mathrm{Ag}$ in close agreement with the theoretical value of $29.07 \%$.

The final intensity data set was collected at 200 $K$ on a CAD 4 diffractometer equipped with a nitrogen gas blower device. A data set collected at room temperature gave very poor resolution of the $\mathrm{C}$-atoms, which is most probably due to conformational reorientations of the ring, similar to that observed in 1-pyrrolidinyldithiocarbamate compounds. ${ }^{4}$ Laue symmetry and systematic extinctions are consistent with the space group $P 2_{1} 2_{1} 2_{1}$. Cell dimensions were obtained from 
Table 1. Crystal data, collection and reduction of intensity data and least-squares refinement.

\begin{tabular}{ll}
\hline Crystal size/mm & $0.42 \times 0.42 \times 0.45$ \\
$a / \AA$ & $7.497(2)$ \\
$b / \AA$ & $11.432(3)$ \\
$c / \AA$ & $15.249(3)$ \\
$V / \AA^{3}$ & 1307 \\
$D_{\mathrm{m}} / \mathrm{g} \mathrm{cm}{ }^{-3}$ & 1.77 \\
$Z$ & 4 \\
$\bar{\lambda} \AA$ & 0.7093 \\
$\mu / \mathrm{cm}^{-1}$ & 18.47 \\
Range of transmission factor & $0.522-0.606$ \\
$\theta$ interval $/$ & $3.0-27.0$ \\
$\omega-2 \theta$ scan width, $\Delta \omega /^{\circ}$ & $0.8+0.5 \tan \theta$ \\
$\sigma_{\mathrm{c}}(I / I$ requested in a scan & 0.030 \\
Maximum recording time $/ \mathrm{s}$ & 120 \\
Number of measured reflexions & 3412 \\
Number of reflexions with $I \geqslant 1.5 \sigma_{\mathrm{c}}(I), m$ & 1368 \\
Number of parameters refined, $n$ & 148 \\
$R=\Sigma\left(\left|F_{\mathrm{o}}\right|-\left|F_{\mathrm{c}}\right|\right) / \Sigma\left|F_{\mathrm{o}}\right|$ & 0.0311 \\
$R_{\mathrm{w}}=\left[\Sigma w\left(\left|F_{\mathrm{o}}\right|-\mid F_{\mathrm{c}} /\right)^{2} / \Sigma w\left|F_{\mathrm{o}}\right|^{2}\right]^{\frac{1}{2}}$ & 0.0309 \\
$S=\left[\Sigma w\left(\left|F_{\mathrm{o}}\right|-\left|F_{\mathrm{c}}\right|\right)^{2} /(m-n)\right]^{\frac{1}{2}}$ & 1.1 \\
\hline
\end{tabular}

Table 2. Positional and isotropic thermal parameters with estimated standard deviations.

$B_{\mathrm{eq}}=\frac{4}{3} \sum \sum \beta_{\mathrm{ij}} a_{\mathrm{i}} \cdot a_{\mathrm{j}}$

\begin{tabular}{lllll}
\hline Atom & $x$ & $y$ & $z$ & $B_{\text {eq/A }} 2$ \\
\hline Ag & $0.3948(1)$ & $0.2709(1)$ & $0.0821(1)$ & $4.29(1)$ \\
S1 & $0.4883(4)$ & $0.3311(2)$ & $0.2289(1)$ & $6.42(7)$ \\
C11 & $0.6375(11)$ & $0.2223(11)$ & $0.2742(5)$ & $8.79(35)$ \\
C12 & $0.5278(20)$ & $0.1577(10)$ & $0.3413(7)$ & $11.22(51)$ \\
C13 & $0.4041(20)$ & $0.2351(12)$ & $0.3750(6)$ & $10.95(44)$ \\
C14 & $0.3167(14)$ & $0.2960(13)$ & $0.3053(5)$ & $11.31(50)$ \\
S2 & $0.0897(2)$ & $0.3363(1)$ & $0.0259(1)$ & $3.80(4)$ \\
C21 & $0.1083(14)$ & $0.4918(6)$ & $-0.0019(5)$ & $5.65(23)$ \\
C22 & $-0.0004(13)$ & $0.5566(8)$ & $0.0656(7)$ & $7.56(32)$ \\
C23 & $-0.0024(14)$ & $0.4884(9)$ & $0.1460(6)$ & $6.95(30)$ \\
C24 & $-0.0437(10)$ & $0.3626(8)$ & $0.1221(5)$ & $5.65(23)$ \\
B & $0.0798(13)$ & $0.0193(7)$ & $0.0963(5)$ & $8.62(22)$ \\
F1 & $-0.0643(9)$ & $0.0763(6)$ & $0.1347(4)$ & $7.18(16)$ \\
F2 & $0.2361(7)$ & $0.0602(5)$ & $0.1333(3)$ & $6.06(14)$ \\
F3 & $0.0771(9)$ & $0.0465(4)$ & $0.0080(3)$ & $8.56(19)$ \\
F4 & $0.0654(9)$ & $-0.0971(4)$ & $0.1070(4)$ & \\
\hline
\end{tabular}

least-squares of $25 \theta$-values determined as $\theta_{h k l}=\left(\omega_{h k l}-\omega_{h k l}^{-l}\right) / 2$ (Table 1). The CAD 4 diffractometer in the bisecting mode, measuring $\omega_{h \bar{k} l}^{-}$at negative $\theta$ angle, was used. During the data collection three standard reflections were measured at regular intervals. No systematic variation in their intensities were observed. Information concerning the collection and reduc- tion of the data is given in Table 1. The values of $I$ and $\sigma_{\mathrm{c}}(I)$ were corrected for Lorentz, polarisation and absorption effects, the latter by numerical integration. The values of $\sigma_{\mathrm{c}}(I)$ are based on counting statistics. Reflections with $I \leqslant 1.5 \sigma_{\mathrm{c}}(I)$ were considered insignificantly different from the background and excluded from all subsequent calculations. The structure was solved by vector 

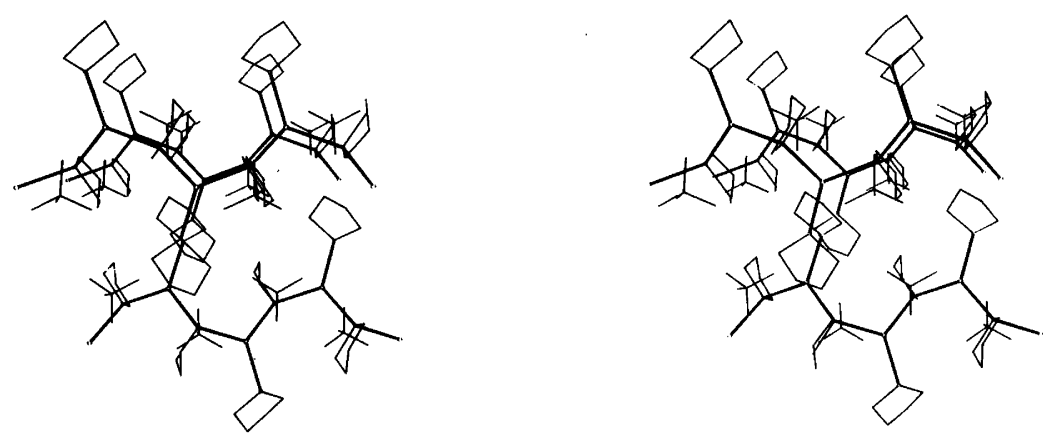

Fig. 1. Stereoscopic packing diagram of $\left[\mathrm{Ag}\left(\mathrm{C}_{4} \mathrm{H}_{8} \mathrm{~S}\right)_{2}\right] \mathrm{BF}_{4}$ viewed along $b$.

and difference Fourier methods. The atomic parameters for non-H atoms were refined using full-matrix least-squares. The atomic parameters of the $\mathrm{H}$-atoms were calculated from the geometric criteria, C-H $0.9 \AA$ and tetrahedral geometry around the $\mathrm{C}$-atoms. These parameters were only included in the structure factor calculations.

The function minimized was $\Sigma w\left(\left|F_{\rho}\right|-\left|F_{\mathrm{c}}\right|\right)^{2}$ with weights $w=\left[\left(\sigma_{\mathrm{c}}^{2} d 4\left|F_{\mathrm{o}}\right|\right)^{2}+\left(0.007\left|F_{\mathrm{o}}\right|\right)^{2}+0.5\right]^{-1}$. In the final refinement anisotropic temperature factors were applied to $\mathrm{Ag}, \mathrm{S}, \mathrm{C}, \mathrm{B}$ and $\mathrm{F}$. Scattering factors with corrections for anomalous dispersion, were taken from International Tables for X-Ray Crystallography. ${ }^{5}$

Details of the refinement are given in Table 1. The final positional and isotropic thermal parameters (anisotropic parameters have been recalculated to isotropic) are given in Table 2 . Table 3 gives selected interatomic distances and angles. A list of structure factors and anisotropic thermal parameters may be obtained from the authors.

\section{DESCRIPTION OF THE CRYSTAL STRUCTURE}

There are two crystallographically different ligands in the structure. The S-atom of ligand 1 is bound only to one $\operatorname{Ag}(I)$ while the S-atom of ligand 2 is bridging two $\operatorname{Ag}(\mathrm{I})$ in such a way as to form infinite chains $\cdots \mathrm{S}-\mathrm{Ag}-\mathrm{S}-\mathrm{Ag} \cdots$ along $a$. (Fig. 1). These chains are van der Waals packed with the $\mathrm{BF}_{4}^{-}$ions in voids in the vicinity of $\mathrm{Ag}(\mathrm{I})$. The $\mathrm{BF}_{4}^{-}$ion is not situated symmetrically between two chains but much closer to one of them. The smallest distances, $\mathrm{B}$ to $\mathrm{Ag}$ in adjacent chains are 3.73 and $6.69 \AA$, respectively. The bridging effect of the anion between the metalligand chains should thus be small.
The true symmetry of the $\mathrm{AgS}_{3}$-core is $C_{1}$ but it may be described as having the pseudosymmetry $D_{3 h}$ (Fig. 2). The three $\mathrm{Ag}-\mathrm{S}$ distances are $2.445(2), 2.519(2)$ and $2.555(2) \AA$, the shortest being associated with the unbridged S-atom. A similar short $\mathrm{Ag}-\mathrm{S}$ bond, $2.457 \AA$, with an unbridged $\mathrm{S}$-atom is observed in the polymer $\cdots\left(\mathrm{F}_{5} \mathrm{C}_{6}\right)_{2} \mathrm{Au}(\mu \text {-AgTHT })_{2} \mathrm{Au}\left(\mathrm{C}_{6} \mathrm{~F}_{5}\right)_{2} \cdots{ }^{6}$ The $\mathrm{S}-\mathrm{Ag}-\mathrm{S}$ angles are in the range $116-125^{\circ}$ and $\mathrm{Ag}$ is situated only $0.06 \AA$ from the plane defined by the S-atoms. If the two $\mathrm{F}$ atoms closest to $\mathrm{Ag}$ ( 2.80 and $2.85 \AA)$ are taken into consideration the coordination polyhedron may be described as a distorted trigonal bipyramide. However, the

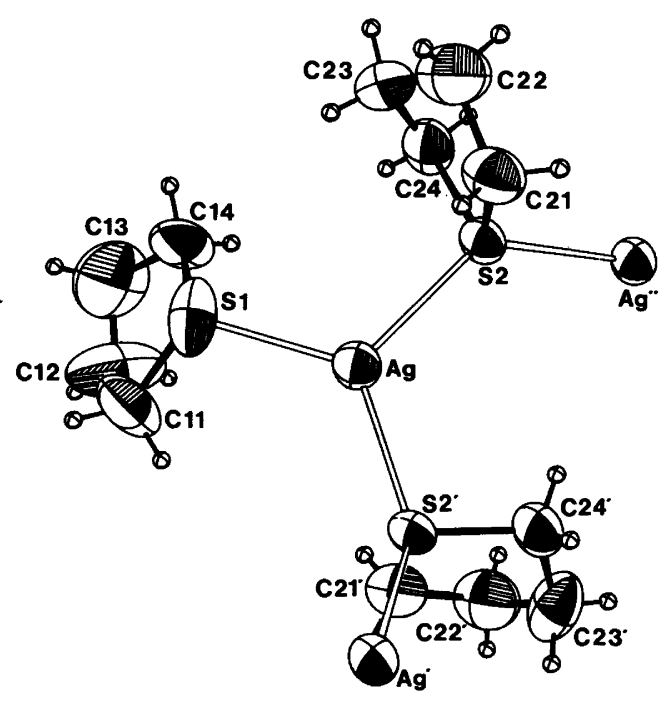

Fig. 2. The coordination around $\mathrm{Ag}$ viewed perpendicular to the LS-plane through Ag, S1, S2 and $\mathbf{S} 2^{\prime}$. 
Table 3. Selected bond distances $(\AA)$ and angles $\left({ }^{\circ}\right)$.

(') $\frac{1}{2}+x, \frac{1}{2}-y,-z\left({ }^{\prime \prime}\right)-\frac{1}{2}+x, \frac{1}{2}-y,-z$

$\begin{array}{lr}a . \text { The coordination polyhedron } \\ \mathrm{Ag}-\mathrm{S} 1 & 2.445(2) \\ \mathrm{Ag}-\mathrm{S} 2 & 2.555(2) \\ \mathrm{Ag}-\mathrm{S} 2^{\prime} & 2.519(2)\end{array}$

$\mathrm{S} 1-\mathrm{Ag}-\mathrm{S} 2$

$\mathrm{S} 1-\mathrm{Ag}-\mathrm{S} 2^{\prime}$

$\mathrm{S} 2-\mathbf{A g}-\mathrm{S2}^{\prime}$

$118.78(7)$

$124.69(8)$

$116.26(3)$

$b$. The THT molecules

S1-C11

$\mathrm{C} 11-\mathrm{C} 12$

$1.810(11)$

$1.507(15)$

$\mathrm{C} 12-\mathrm{C} 13$

$1.380(19)$

C13-C14

$1.429(16)$

C14-S1

$1.781(10)$

$\mathrm{S} 2-\mathrm{C} 21$

$1.832(7)$

$\mathrm{C} 21-\mathrm{C} 22$

$1.507(14)$

$\mathrm{C} 22-\mathrm{C} 23$

$1.454(14)$

$\mathrm{C} 23-\mathrm{C} 24$

$1.516(14)$

C24-S2

1.802(8)

S1-C11-C12

105.0(7)

$\mathrm{C} 11-\mathrm{C} 12-\mathrm{C} 13$

$107.8(10)$

$\mathrm{C} 12-\mathrm{C} 13-\mathrm{C} 14$

$110.1(9)$

C13-C14-S1

105.4(8)

C14-S1-C11

$92.4(5)$

S2-C21-C22

106.1(6)

$\mathrm{C} 21-\mathrm{C} 22-\mathrm{C} 23$

$108.5(8)$

$\mathrm{C} 22-\mathrm{C} 23-\mathrm{C} 24 \quad 108.0(8)$

$\mathrm{C} 23-\mathrm{C} 24-\mathrm{S} 2$

C24-S2-C21

$103.9(6)$

94.0(4)

$\begin{array}{ll}c . \text { The } \mathrm{BF}_{4}^{-} \text {ion } & \\ \text { B-F1 } & 1.391(11) \\ \text { B-F2 } & 1.382(11) \\ \text { B-F3 } & 1.383(9) \\ \text { B-F4 } & 1.344(9)\end{array}$

F1-B-F2

F1-B-F3

109.1(6)

$\mathrm{F} 1-\mathrm{B}-\mathrm{F} 4$

$107.0(7)$

F2-B-F3

$110.5(7)$

F2-B-F4

$109.5(7)$

$110.8(7)$

$d$. Bond angles around the $S$ atoms
Ag-S1-C11
$\mathrm{Ag}-\mathrm{S} 1-\mathrm{Cl} 4$
$109.5(3)$
C11-S1-C14
$109.2(3)$

$\mathrm{Ag}-\mathrm{S} 2-\mathrm{Ag}^{\prime \prime}$

$\mathrm{Ag}-\mathrm{S} 2-\mathrm{C} 21$

$\mathrm{Ag}-\mathrm{S} 2-\mathrm{C} 24$

$\mathrm{Ag}^{\prime \prime}-\mathrm{S} 2-\mathrm{C} 21$

$\mathrm{Ag}^{\prime \prime}-\mathrm{S} 2-\mathrm{C} 24$

C21-S2-C24

$126.59(7)$

107.1(3)

$105.8(3)$

$111.4(3)$

$106.9(3)$

94.0(4)

Ag $\cdots$ F interactions must be considered very weak and will not be taken into account in the discussion of the coordination geometry of $\mathrm{Ag}$.

With the exception of two very short $\mathrm{C}-\mathrm{C}$ distances, $C_{12}-C_{13}$ and $C_{13}-C_{14}$, bond distances and angles in the two THT-ligands are not significantly different (Table 3 ) and they agree well with those observed in other compounds. ${ }^{7}$ The very short $\mathrm{C}-\mathrm{C}$ distances observed are most probably an artifact caused by thermal motion. ${ }^{4}$ Bond distances and angles within the $\mathrm{BF}_{4}^{-}$ion are of the expected magnitudes. ${ }^{8}$

\section{DISCUSSION}

In a qualitative valence-bond description bond angles are highly dependent on hybridization of the atom under consideration. In the present case the bond angles around $\mathrm{Ag}$ are close to $120^{\circ}$ and the bonding to $\mathrm{Ag}$ may in such a model be described as three $\sigma$-bonds donated into $s p^{2}$ orbitals of the metal ion.

The bonding situation for the S-atoms in the two THT-ligands is different, S1 is bonded to three atoms while $S 2$ is bonded to four. The bond angles around $\mathrm{S} 1$ are in the range $92-109^{\circ}$ (Table $3)$. The $S 1$ atom may thus be regarded as $s p^{3}$-hybridized with three electron pairs participating in $\sigma$-bonds and one essentially nonbonding. For $\mathbf{S} 2$ all four electron pairs participate in $\sigma$-bonds. The fairly large $\mathrm{Ag}-\mathrm{S} 2-\mathrm{Ag}$ angle, $126.6^{\circ}$ (Table 3 ), may be a consequence of the very small angle $\mathrm{C} 21-\mathrm{S} 2-\mathrm{C} 24,94.0^{\circ}$. Thus there is no indication of $\pi$-bonding in the studied compound.

The coordination situation in the present compound may be compared with the coordination to 


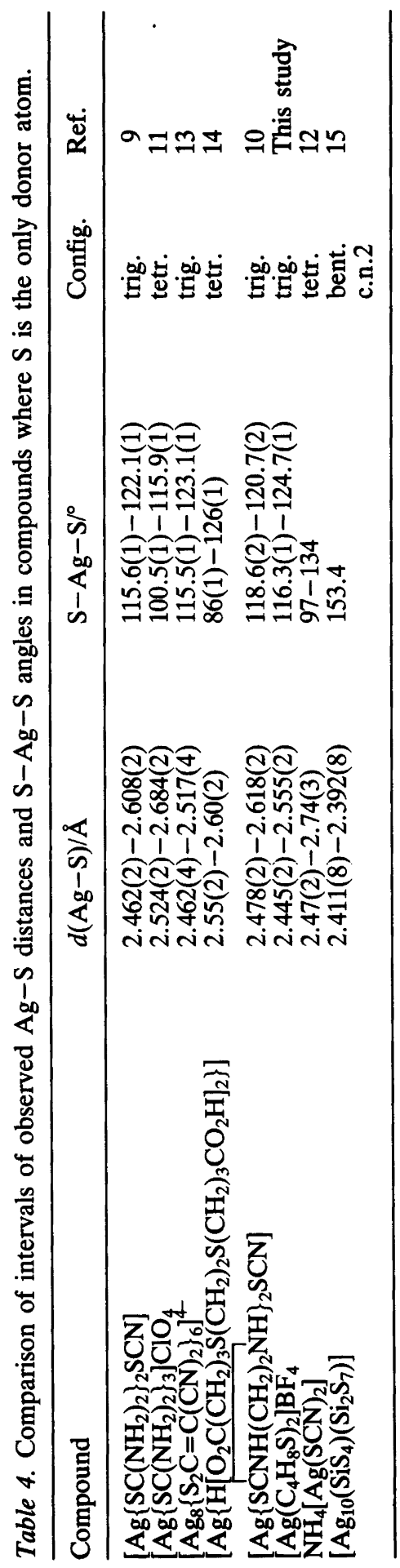

$\mathrm{Ag}(\mathrm{I})$ of the ligands thiourea, $\mathrm{SC}\left(\mathrm{NH}_{2}\right)_{2}$ and 2-thioimidazolidine, $\mathrm{SCNH}\left(\mathrm{CH}_{2}\right)_{2} \mathrm{NH}$. With $\mathrm{SCN}^{-}$these ligands form trigonal planar complexes with $\operatorname{Ag}(\mathrm{I})$, one of the coordinating sites being occupied by $\mathrm{S}$ from $\mathrm{SCN}^{-} ., 10$ The $\mathrm{S}$ atoms in $\mathrm{SC}\left(\mathrm{NH}_{2}\right)_{2}$ and $\mathrm{SCNH}\left(\mathrm{CH}_{2}\right)_{2} \mathrm{NH}$ may be regarded as $\mathrm{sp}^{2}$ hybridized, with lone pairs suitable for $\sigma$-bonds to $\operatorname{Ag}(I)$. Both molecules also have extensive $\pi$-electron systems capable of participating in $\pi$-bonding with $\operatorname{Ag}(\mathrm{I})$. That $\pi$-bonding actually is of some significance in these compounds is supported by the observed angles between the least-square planes through the sulfur, carbon and nitrogen atoms of the thiourea parts of the ligands and the plane formed by the sulfur and silver atoms in the coordination polyhedra, which are less than $14^{\circ}$ in both compounds. It may thus be concluded that three-coordination around $\mathrm{Ag}(\mathrm{I})$ with $\mathrm{S}$-atoms occurs both with ligands forming and not forming $\pi$-bonds with $\mathrm{Ag}(\mathrm{I})$.

In Table 4 the coordination characteristics for some compounds in which $\mathrm{Ag}(\mathrm{I})$ is exclusively coordinating $\mathrm{S}$ are given. It is interesting to note that in the presence of the non-coordinating anion $\mathrm{ClO}_{4}^{-}, \mathrm{Ag}(\mathrm{I})$ and $\mathrm{SC}\left(\mathrm{NH}_{2}\right)_{2}$ form a dimeric unit $\left[\mathrm{Ag}_{2}\left\{\mathrm{SC}\left(\mathrm{NH}_{2}\right)_{2}\right\}_{6}\right]^{2+}$ in which $\mathrm{Ag}(\mathrm{I})$ is tetrahedrally coordinated by four S-atoms. ${ }^{11}$ From this Table it may be concluded that $\mathrm{Ag}(\mathrm{I})$ is quite variable in its coordination geometry, varying between bent (c.n. 2), trigonal planar (c.n. 3) and tetrahedral (c.n. 4).

Acknowledgements. We wish to thank Professor Sten Ahrland for helpful discussions, advice and kind interest in this work. We are further indebted to Ms Lena Timby for her skillful technical assistance.

\section{REFERENCES}

1. Pearson, R. G. J. Am. Chem. Soc. 85 (1963) 3533.

2. Ahrland, S. Pure Appl. Chem. 51 (1979) 2019.

3. Gran, G. Acta Chem. Scand. 4 (1950) 559.

4. Albertsson, J., Oskarsson, Å., Ståhl, K., Svensson, C. and Ymén, I. Acta Crystallogr. $B 36$ (1980) 3072.

5. International Tables for $X$-Ray Crystallography, Kynoch Press, Birmingham 1974, Vol. 
6. Uson, R., Laguna, A., Laguna, M., Jones, P. G. and Sheldrick, G. M. J. Chem. Soc. Chem. Commun. (1981) 1097.

7. Cotton, F. A. and Najjar, R. C. Inorg. Chem. 20 (1981) 2716.

8. Taylor, I. F., Weininger, M. S. and Amma, E. L. Inorg. Chem. 13 (1974) 2835.

9. Udupa, M. R., Henkel, G. and Krebs, B. Inorg. Chim. Acta 18 (1976) 173.

10. Ferrari, M. B., Fava, G. G. and Tani, M. E. V. Cryst. Struct. Commun. 10 (1981) 571.

11. Udupa, M. R. and Krebs, B. Inorg. Chim. Acta 7 (1973) 271.

12. Lindquist, I. and Strandberg, B. Acta Crystallogr. 10 (1957) 173.

13. Birker, P. J. M. W. L. and Verschoor, G. C. J. Chem. Soc. Chem. Commun. (1981) 322.

14. Hittenhausen, $H$. and van der Meer, $H$. Cryst. Struct. Commun. 7 (1978) 385.

15. Mandt, J. and Krebs, B. Z. Anorg. Allg. Chem. 420 (1976) 31.

Received November 7, 1983. 